\title{
A Family Study of Obsessive-Compulsive Disorder With Pediatric Probands
}

\author{
Gregory L. Hanna, ${ }^{1 *}$ Joseph A. Himle, ${ }^{1}$ George C. Curtis, ${ }^{1}$ and Brenda W. Gillespie ${ }^{2}$ \\ ${ }^{1}$ Department of Psychiatry, University of Michigan Medical School, Ann Arbor, Michigan \\ ${ }^{2}$ Department of Biostatistics, University of Michigan School of Public Health, Ann Arbor, Michigan
}

\begin{abstract}
Obsessive-compulsive disorder (OCD) is a heterogeneous disorder of unknown etiology. We examined the lifetime history of obsessions, compulsions, and OCD in the first- and second-degree relatives of 35 pediatric probands with $O C D$ and 17 controls with no psychiatric diagnosis. All available first-degree relatives were directly interviewed blind to proband status with two semi-structured interviews. Parents were also interviewed to systematically assess the family psychiatric history of first- and second-degree relatives. Best-estimate lifetime diagnoses were made using all available sources of information. Data were analyzed with logistic regression by the generalized estimating equation method and with robust Cox regression models. The lifetime prevalence of definite OCD was significantly higher in case than control first-degree relatives $(22.5 \%$ vs. $2.6 \%, P<0.05)$. Compared to controls, case firstdegree relatives also had significantly higher lifetime rates of obsessions and compulsions (both $P<0.05$ ). There was no significant difference between case and control second-degree relatives in lifetime rates of OCD. First-degree relatives of case probands with ordering compulsions had a significantly higher lifetime rate of definite and subthreshold OCD than relatives of case probands without ordering compulsions $(45.4 \%$ vs. $18.8 \%$, $P<0.05)$. The lifetime prevalence of definite OCD was significantly higher in case first-degree relatives with a history of tics than in case first-degree relatives without a tic history $(57.1 \%$ vs. $20.9 \%$, $P<0.01)$. The results provide further evidence that early-onset OCD is highly familial and suggest that two clinical variables are associated with its familial aggregation.

(C) 2005 Wiley-Liss, Inc.
\end{abstract}

KEY WORDS: obsessive-compulsive disorder; tic disorders; age at onset; family study; logistic regression

\section{DATABASE: OCD}

Grant sponsor: NIH (to G.L.H.); Grant numbers: K20 MH01065, R01 MH58376.

*Correspondence to: Gregory L. Hanna, M.D., Department of Psychiatry, University of Michigan Health System, 2101 Commonwealth Boulevard, Suite C, Ann Arbor, Michigan 48109-0390. E-mail: ghanna@umich.edu

Received 22 July 2004; Accepted 20 September 2004

DOI 10.1002/ajmg.b.30138

\section{INTRODUCTION}

Obsessive-compulsive disorder (OCD [MIM 164230]) is a heterogeneous psychiatric disorder of unknown etiology. Estimates of its lifetime prevalence in adolescents and adults range from $1 \%$ to $3 \%$ [Zohar et al., 1992; Valleni-Basile et al., 1994; Weissman et al., 1994]. The average age at onset in epidemiological studies of OCD is in early adulthood [Burke et al., 1990; Weissman et al., 1994]. Males generally have earlier onset than females, contributing to a preponderance of males in most pediatric samples [Geller et al., 1998]. In contrast, there is a slight preponderance of females in most adult samples [Weissman et al., 1994]. Although obsessivecompulsive (OC) symptoms are virtually identical in children and adults, there are important clinical differences between early- and late-onset OCD. Early-onset OCD has been associated with higher symptom severity ratings, higher rates of compulsions without obsessions, higher rates of OC symptoms unrelated to duration of illness, and comorbid tic disorders [Geller et al., 1998; Sobin et al., 2000; RosarioCampos et al., 2001].

Twin and family studies provide evidence that genetic factors are involved in the transmission and expression of OCD. Estimates of the heritability of OC symptoms range from $26 \%$ to $47 \%$ [Clifford et al., 1984; Jonnal et al., 2000]. A metaanalysis of data from five family studies with adult probands found a summary odds ratio (OR) of 4.0 for OCD in case and control first-degree relatives [Hettema et al., 2001]. An early age at onset of OC symptoms in family studies with adult probands is strongly associated with a more familial form of OCD [Bellodi et al., 1992; Pauls et al., 1995; Nestadt et al., 2000]. An early-onset age of OC symptoms in adult probands is also associated with higher prevalence rates of tics and Tourette's disorder in family members [Pauls et al., 1995; Grados et al., 2001]. However, family studies with pediatric probands have often lacked control groups and have yielded divergent results, with rates of OCD in case first-degree relatives ranging from $5 \%$ to $17 \%$ [Lenane et al., 1990; Leonard et al., 1992; Thomsen, 1995; Reddy et al., 2001].

In addition to onset age of OC symptoms, two other clinical variables may be associated with the familial aggregation of OCD. First, a segregation analysis found that the relative risk of OCD was higher in relatives of probands with higher factor scores for symmetry and ordering symptoms than in relatives of probands with lower scores, and concluded that there was evidence for a major locus only in the analysis limited to families of OCD probands with high rates of symmetry and ordering symptoms [Alsobrook et al., 1999]. The findings suggest that symmetry and ordering symptoms may constitute a genetically significant symptomatic subtype of OCD [Alsobrook et al., 1999]. Second, two family studies found that tic disorders are more to likely to occur in case relatives with OCD than in case relatives without OCD [Pauls et al., 1995; Grados et al., 2001]. The results indicate that there is a bidirectional relationship between OCD and tic disorders in relatives of OCD probands. 
We conducted the following study to examine the familiality of early-onset OCD. The primary goal was to assess the familiality of obsessions, compulsions, and OCD in first- and second-degree relatives. The secondary goal was to determine whether three clinical variables (age at onset of OC symptoms in case probands, ordering compulsions in case probands, and tic disorders in case first-degree relatives) are associated with the familial aggregation of the disorder.

\section{MATERIALS AND METHODS}

\section{Subject Ascertainment}

We ascertained 35 case and 17 control families through probands between the ages of 10 and 17 years. The ascertainment and diagnostic procedures used in the study have been described previously [Hanna et al., 2002]. The case probands had a current diagnosis of OCD and were recruited from clinics in the University of Michigan Health System and local chapters of the Obsessive-Compulsive Foundation. The control probands were recruited from advertisements in local newspapers and bulletins posted at the University of Michigan. All probands were directly interviewed to determine whether they met DSM-III-R criteria for OCD [American Psychiatric Association, 1987]. Exclusion criteria for the case probands were (1) DSM-III-R diagnosis of mental retardation, autistic disorder, schizophrenia, or bipolar disorder, (2) currently living away from both biological parents, and (3) adoption. Exclusion criteria for the control probands were (1) any DSMIII-R disorder as well as (2) and (3) as above. Written informed consent was obtained from both parents and informed assent from probands. The study was approved by the Institutional Review Board of the University of Michigan.

After completing the proband diagnostic evaluation, permission to contact other relatives was requested from the parents. Direct diagnostic interviews were completed with 203 individuals (all 52 probands, 136 first-degree relatives, 15 seconddegree relatives). The sample did not include four directly interviewed individuals because genotyping indicated nonpaternity within a family [Hanna et al., 2002]. Diagnostic information was also collected from parents or spouses on 644 individuals (all 52 probands, 133 first-degree relatives, 459 second-degree relatives). This process provided diagnostic information on five first-degree relatives without direct interviews and 444 second-degree relatives without direct interviews for a total of 449 relatives with only family informant data.

\section{Diagnostic Procedures}

After informed consent and assent were obtained, probands and siblings between 10 and 17 years of age were interviewed with the Schedule for Affective Disorders and Schizophrenia for School Age Children-Epidemiologic Version [Orvaschel, 1987]. Individuals younger than 10 years were not included in the study. The interview was completed independently with a parent of the subject as well as with the subject. It was supplemented with sections on OCD and tic disorders from the Schedule for Tourette and Other Behavioral Syndromes (STOBS) [Pauls and Hurst, 1991; Pauls et al., 1995]. Relatives 18 years and older were interviewed with the Structured Clinical Interview for DSM-III-R [Spitzer et al., 1990] and sections on OCD and tic disorders from the STOBS.

The OCD sections included a series of screening questions designed to cover all criteria for a DSM-III-R diagnosis of OCD [Pauls et al., 1995] and a checklist from the Yale-Brown Obsessive Compulsive Scale [Goodman et al., 1989] modified to obtain information about the lifetime occurrence of obsessions and compulsions. Categorizations of OC symptoms were made according to checklist subheadings to standardize the record- ing of the symptoms. Tics were assessed by examination and interview, and characterized using the DSM-III-R definition of "involuntary, sudden, rapid, recurrent, non-rhythmic, stereotyped" motor movements or vocalizations [American Psychiatric Association, 1987]. Tics were distinguished from "tic-like" compulsions based on whether the patient attached a meaning or purpose to the behavior.

Further information on relatives 18 years and older was obtained with the Family Informant Schedule and Criteria (FISC) [Mannuza et al., 1985]. The mother of each proband was interviewed with the FISC regarding her spouse, adult offspring, parents, and siblings. The father of each proband was interviewed with the FISC regarding his spouse, parents, and siblings. Thus, two types of information were obtained on directly interviewed adult subjects: (1) data from structured interviews and (2) personal history data from a biological relative and/or spouse.

All interviews were audiotaped as well as coded on paper. All interviewers had at least a master's degree and clinical training in either child or adult psychopathology. They were trained to at least $90 \%$ diagnostic agreement with the individual instruments. The interviewers were limited to interviewing either probands and their relatives between 10 and 17 years of age or adult relatives. The interviewer for a given proband was not involved with the interviews of other family members. After completion of all interviews for an individual, all available materials (personal interview data, family history data, audiotapes, and clinical records) were collated. All information identifying or describing the proband was removed so that diagnostic ratings could be completed by raters blind to proband diagnosis. The blinded diagnosticians were never given a complete family to evaluate at one time, and all proband diagnostic evaluations were done separately from those of their relatives.

Best-estimate lifetime diagnoses were made independently for directly interviewed subjects by two investigators using DSM-III-R criteria. Definite OCD was diagnosed only if a directly interviewed subject met all diagnostic criteria. Subthreshold OCD was diagnosed if a directly interviewed subject met criteria for definite obsessions and/or compulsions, but lacked compelling evidence for any of the following criteria: (1) marked distress, (2) duration of OC symptoms for more than one hour a day, or (3) significant interference in the person's normal routine, occupational (or academic) functioning, or usual social activities or relationships with others. To avoid forcing closure on inadequate diagnostic information, subjects were re-interviewed if necessary to clarify incomplete or contradictory information. When disagreements occurred between two diagnosticians, consensus diagnoses were reached with the assistance of a third diagnostician following established procedures developed for the diagnosis of other psychiatric disorders [Leckman et al., 1982]. The interrater reliability of this diagnostic process was studied in a sample of 108 subjects. There was good diagnostic agreement, as evidenced by a $\kappa=0.91$ for OCD, a $\kappa=0.91$ for tic disorder, and an intraclass correlation coefficient of 0.94 for age at onset of OC symptoms.

\section{Statistical Analyses}

The demographic characteristics of case and control probands and of case and control relatives were compared using $\chi^{2}$ or Fisher exact tests [Fleiss, 1973] for categorical data and $t$ tests for continuous data. Unadjusted lifetime rates of obsessions, compulsions, OCD, and tic disorders in case and control relatives were compared by $\chi^{2}$ tests with 1 degree of freedom for $2 \times 2$ tables. The odds of obsessions, compulsions, OCD, and tic disorders in case versus control relatives were estimated using logistic regression by the generalized estimating equation 
(GEE) method, which accounts for within-family correlations among relatives [Liang and Pulver, 1996]. Predictors of definite OCD in case first-degree relatives were examined also using logistic regression by the GEE method. Four proband characteristics (gender, onset age of OC symptoms, history of ordering compulsions, and lifetime diagnosis of tic disorder) and three first-degree relative characteristics (age, gender, and lifetime diagnosis of tic disorder) were entered as independent variables. No other OC symptom categories or comorbid diagnoses were examined as possible predictors.

Age-corrected lifetime rates of obsessions, compulsions, and OCD among relatives were compared by Cox proportional hazards $(\mathrm{PH})$ regression, a semi-parametric regression model for survival data [Cox, 1972]. Robust Cox regression was used to control for the familial dependency of observations in relatives, which may be more appropriate than logistic regression for analyzing data from subjects still at risk for developing OCD in that it censors subjects who have not developed OCD by the interview age. The $\mathrm{PH}$ procedure yields a ratio of the hazards for two levels of a predictor variable while simultaneously controlling for potentially confounding variables. Two potentially confounding covariates, age and gender of relative, were controlled by including terms for these variables in $\mathrm{PH}$ models. We assume that the hazard ratio (HR) is constant over all ages, although this assumption can be relaxed in more complex models. The null hypothesis of homogeneity in cumulative survival curves was tested using the log-rank test [Mantel, 1966]. Age-corrected occurrence risks were estimated using Kaplan-Meier survival analyses of the time to OC symptom onset [Lee and Go, 1997]. Analyses were performed with SAS software [SAS Institute, Inc., 1997]. All tests were two-tailed with $\alpha=0.05$.

\section{RESULTS}

\section{Characteristics of the Study Sample}

The total sample had 652 individuals, consisting of 35 case probands ( 25 male, 10 female), 102 case first-degree relatives (34 fathers, 35 mothers, 18 brothers, 15 sisters), 309 case second-degree relatives, 17 control probands ( 10 male, 7 female), 39 control first-degree relatives (17 fathers, 17 mothers, 4 brothers, 1 sister), and 150 control second-degree relatives.

All case probands and 98 (96\%) of the 102 case first-degree relatives were directly interviewed. Family informant information was obtained for the four case first-degree relatives without direct interviews. All control probands and $38(97 \%)$ of the 39 control first-degree relatives were directly interviewed. Family informant information was obtained for the one control first-degree relative without a direct interview. There was no significant difference between the case and control first-degree relatives in the proportion of directly interviewed subjects
$(P=0.70)$. Of the 309 case second-degree relatives, $14(4.5 \%)$ were directly interviewed and family informant data were collected for the 295 relatives without direct interviews. Of the 150 control second-degree relatives, only one $(0.7 \%)$ was directly interviewed and family informant data were collected for the 149 relatives without direct interviews. This resulted in a significant difference between the case and control seconddegree relatives in the proportion of directly interviewed subjects $(P<0.05)$.

As presented in Table I, $71 \%$ of the case probands and $59 \%$ of the control probands were male. One case and one control proband were African American. The case probands ranged in age from 10 to 17 years. The control probands ranged in age from 10 to 15 years. There was a trend for case probands to be older than control probands at the time of interview $(P=0.055)$.

Onset age of $\mathrm{OC}$ symptoms in the case probands ranged from 4 to 14 years, with a median onset age of about 9 years. The mean age at onset was similar in male and female case probands $(8.84 \pm 3.11$ vs. $9.26 \pm 3.62$ years, mean $\pm \mathrm{SD}$; $\left.\mathrm{t}_{33}=0.35 ; P=0.73\right)$. Fourteen case probands $(40 \%)$ had a lifetime diagnosis of tic disorder. Case probands with a history of tics had a significantly earlier onset age of OC symptoms than did those without a tic history $(6.82 \pm 3.01$ vs. $10.38 \pm$ 2.53 years, mean $\left.\pm \mathrm{SD} ; \mathrm{t}_{33}=3.78 ; P=0.0006\right)$. Onset age of $\mathrm{OC}$ symptoms in case probands was not associated with whether their first-degree relatives had a history of tics.

Table II describes the demographic characteristics of the case and control first-degree relatives. The case first-degree relatives ranged in age from 10 to 57 years. The control firstdegree relatives ranged in age from 10 to 56 years. The distribution of the type of relative was significantly different between the two groups in that children comprised a smaller proportion of control than case first-degree relatives $(P<0.05)$. The mean number of assessed first-degree relatives was significantly higher in case than in control families $\left(t_{50}=\right.$ $2.80, P<0.01)$.

The case second-degree relatives ranged in age from 12 to 88 years. The control second-degree relatives ranged in age from 20 to 91 years. There were no significant differences between the case and control second-degree relatives in gender distribution, age, distribution of the type of relatives, or mean number of second-degree relatives in a family.

\section{Prevalence and Odds of Obsessions, Compulsions, OCD, and Tic Disorders in Relatives}

Table III presents the rates of obsessions, compulsions, OCD, and tic disorders in 141 first-degree relatives. Complete diagnostic data from direct interviews were available for obsessions, compulsions, and tics in 136 first-degree relatives. The lifetime prevalence of definite OCD was substantially

TABLE I. Demographic Characteristics of Case and Control Probands

\begin{tabular}{lcccc}
\hline & $\begin{array}{c}\text { Case probands } \\
(\mathrm{N}=35)\end{array}$ & $\begin{array}{c}\text { Control probands } \\
(\mathrm{N}=17)\end{array}$ & Test statistic $^{\mathrm{a}}$ & $P$ \\
\hline Gender, N (\%) & $25(71)$ & $10(59)$ & $\chi^{2}{ }_{1}=0.83$ & 0.363 \\
$\quad$ Male & $10(29)$ & $7(41)$ & & \\
$\quad$ Female & $13.7(2.4)$ & $12.4(1.8)$ & $\mathrm{t}_{50}=1.97$ & 0.055 \\
Mean (SD) age, years & $34(97)$ & $16(94)$ & $\chi^{2}{ }_{1}=0.28$ & 0.595 \\
Caucasian, N (\%) & $20(57)$ & $10(59)$ & & \\
Social class N (\%) & $9(26)$ & $6(35)$ & Fisher's Exact Test & 0.588 \\
$\quad$ I and II, highest & $6(17)$ & $1(6)$ & & \\
III & & & \\
IV and V, lowest &
\end{tabular}

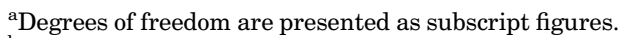

${ }^{\mathrm{b}}$ Hollingshead [1965] index. 
TABLE II. Demographic Characteristics of Case and Control First-Degree Relatives

\begin{tabular}{lcccc}
\hline & $\begin{array}{c}\text { Case relatives } \\
(\mathrm{N}=102)\end{array}$ & $\begin{array}{c}\text { Control relatives } \\
(\mathrm{N}=39)\end{array}$ & $\begin{array}{c}\text { Test } \\
\text { statistic* }^{*}\end{array}$ & $P$ \\
\hline Gender, N (\%) & $52(51)$ & $21(54)$ & $\chi^{2}{ }_{1}=0.09$ & 0.761 \\
$\quad$ Male & $50(49)$ & $18(46)$ & & \\
$\quad \begin{array}{l}\text { Female } \\
\text { Mean (SD) age, years }\end{array}$ & $36.1(13.4)$ & $39.8(11.8)$ & $\mathrm{t}_{139}=1.51$ & 0.134 \\
$\begin{array}{l}\text { Type of relative, N }(\%) \\
\text { Parents with diagnostic data }\end{array}$ & $69(68)$ & $34(87)$ & $\chi^{2}{ }_{1}=5.47$ & 0.019 \\
$\quad \begin{array}{c}\text { Siblings with diagnostic data } \\
\text { Mean (SD) number assessed in }\end{array}$ & $33(32)$ & $5(13)$ & & \\
$\quad$ family & $2.9(1.1)$ & $2.3(0.5)$ & $\mathrm{t}_{50}=2.80$ & 0.007 \\
\hline
\end{tabular}

*Degrees of freedom are presented as subscript figures.

higher in case than control first-degree relatives $(22.5 \%$ vs. $2.6 \%$ ). The ratio of the rates of definite OCD in case and control first-degree relatives (relative risk or estimated $\lambda$ ) was 8.65. The difference between case and control first-degree relatives increased when subthreshold OCD was included in the phenotype (27.4\% vs. $2.6 \%$ ), yielding a relative risk of 10.54 . The lifetime prevalence of definite obsessions was considerably higher in case than control first-degree relatives $(20.4 \%$ vs. $2.6 \%$ ), as was the lifetime prevalence of definite compulsions $(22.4 \%$ vs. $2.6 \%)$. In contrast to the OCD phenotypes, the lifetime prevalence of chronic tic disorders (Tourette's disorder and chronic motor or vocal tic disorder) and tic disorders altogether was only slightly higher in case than in control first-degree relatives $(4.1 \%$ vs. $2.6 \%$ and $7.1 \%$ vs. $5.3 \%$, respectively).

The odds of definite OCD was 11 times greater in case than control first-degree relatives $(\mathrm{OR}=11.06,95 \%$ confidence interval $(\mathrm{CI})=1.44-85.01, P=0.021)$. Significant ORs were found for all definitions of the OCD phenotype, indicating that case first-degree relatives met criteria for OCD-related phenotypes significantly more often than control firstdegree relatives. The magnitude of the associations for definite obsessions and definite compulsions were equally robust. The significant differences between case and control relatives in definite OCD as well as in definite and subthreshold OCD were confirmed with univariate robust Cox regression $(\mathrm{HR}=9.84$, $95 \% \mathrm{CI}=7.04-12.63, P=0.026$ and $\mathrm{HR}=12.40,95 \% \mathrm{CI}=$ $9.61-15.20, P=0.014$, respectively). In contrast to the ORs for OCD phenotypes, the ORs for chronic tic disorders and all tic disorders were not statistically significant.

Table IV indicates that the odds of definite OCD between the two groups of first-degree relatives remained almost the same while controlling for the age and gender of the relative in a multivariable model $(\mathrm{OR}=10.94,95 \% \mathrm{CI}=1.44-82.77$,
$P=0.021$ ). Type of interview was not included since almost all first-degree relatives were directly interviewed; the results did not change substantially with type of interview included in the multivariable model (data not shown). The significant difference between case and control relatives in definite OCD while controlling for the age and gender of the relative was confirmed with multivariate robust Cox regression using the Breslow method for ties $(\mathrm{HR}=9.92,95 \% \mathrm{CI}=7.11-12.73, P=0.026)$.

The lifetime prevalence of definite OCD was not significantly increased in the case second-degree relatives compared to controls $(1.6 \%$ vs. $0.7 \%, \mathrm{OR}=2.45,95 \% \mathrm{CI}=0.28-21.38$, $P=0.417$ ). By adding subthreshold OCD to the phenotype, the difference between the two groups remained non-significant $(3.2 \%$ vs. $0.7 \%, \quad \mathrm{OR}=4.98, \quad 95 \% \quad \mathrm{CI}=0.64-38.91$, $P=0.126)$

\section{Prevalence of OCD in Case First-Degree Relatives by Clinical Characteristics}

Predictors of definite OCD in case first-degree relatives were assessed using logistic regression by the GEE method. The variables consisted of four proband characteristics (gender, onset age of OC symptoms, history of ordering compulsions, lifetime diagnosis of tic disorder) and three first-degree relative characteristics (gender, current age, lifetime diagnosis of tic disorder). Ordering compulsions in probands $(\mathrm{OR}=1.17,95 \%$ $\mathrm{CI}=1.02-1.34, P=0.021)$ and tic disorders in relatives $(\mathrm{OR}=1.40,95 \% \mathrm{CI}=1.04-1.89, P=0.025)$ were significant predictors of definite OCD in case first-degree relatives. Elimination of other variables from the model increased the ORs for ordering compulsions in probands and tic disorders in relatives (data not shown). Multivariate robust Cox regression using the Breslow method for ties confirmed that tics in case first-degree relatives were a significant predictor of definite

TABLE III. Prevalence of Obsessions, Compulsions, Obsessive-Compulsive Disorder (OCD), and Tic Disorders in 141 First-Degree Relatives

\begin{tabular}{|c|c|c|c|c|}
\hline Phenotype of first-degree relative & $\begin{array}{c}\text { Case relatives } \\
\text { affected, } \mathrm{N}(\%)^{\mathrm{a}}\end{array}$ & $\begin{array}{l}\text { Control relatives } \\
\text { affected, } \mathrm{N}(\%)^{\mathrm{b}}\end{array}$ & Odds ratio $^{c}(95 \% \mathrm{CI})$ & $P$ \\
\hline OCD (definite) & $23(22.5)$ & $1(2.6)$ & $11.06(1.44,85.01)$ & 0.021 \\
\hline OCD (definite and subthreshold) & $28(27.4)$ & $1(2.6)$ & $14.38(1.88,109.77)$ & 0.010 \\
\hline Obsessions (definite) & $20(20.4)$ & $1(2.6)$ & $9.49(1.23,73.41)$ & 0.031 \\
\hline Obsessions (definite and subthreshold) & $28(28.6)$ & $2(5.3)$ & $7.20(1.62,31.94)$ & 0.009 \\
\hline Compulsions (definite) & $22(22.4)$ & $1(2.6)$ & $10.71(1.30,82.55)$ & 0.023 \\
\hline Compulsions (definite and subthreshold) & $28(28.6)$ & $4(10.5)$ & $3.40(1.10,10.47)$ & 0.033 \\
\hline Tourette's disorder and CMVT disorder & $4(4.1)$ & $1(2.6)$ & $1.57(0.20, \infty)$ & 0.570 \\
\hline All tic disorders & $7(7.1)$ & $2(5.3)$ & $1.38(0.24,7.83)$ & 0.713 \\
\hline
\end{tabular}

CI, confidence interval; CMVT disorder, chronic motor or vocal tic disorder.

aThe number of case relatives with complete diagnostic information for obsessions, compulsions, and tics was 98 .

${ }^{b}$ The number of control relatives with complete diagnostic information for obsessions, compulsions, and tics was 38

'Estimated using the generalized estimating equation method. 
TABLE IV. Odds Ratios for Definite OCD in 141 First-Degree Relatives Using a Multivariable Model

\begin{tabular}{lcc}
\hline $\begin{array}{l}\text { Characteristic of } \\
\text { first-degree relative }\end{array}$ & Odds ratio $(95 \% \mathrm{CI})^{\mathrm{a}}$ & $P$ \\
\hline $\begin{array}{l}\text { Group } \\
\text { Case }\end{array}$ & $10.94(1.44,82.77)$ & 0.021 \\
$\quad$ Control & 1.0 & \\
$\begin{array}{l}\text { Gender } \\
\quad \text { Male }\end{array}$ & $1.62(0.64,4.11)$ & 0.307 \\
$\quad \begin{array}{c}\text { Female } \\
\text { age at interview } \\
\quad \text { per year increase) }\end{array}$ & $0.997(0.96,1.02)$ & 0.613 \\
\end{tabular}

CI, confidence interval.

${ }^{a}$ Determined using logistic regression by the generalized estimating equation method.

${ }^{\mathrm{b}}$ Reference group.

OCD in those relatives $(\mathrm{HR}=3.98,95 \% \mathrm{CI}=2.29-5.67$, $P=0.008$ ). However, ordering compulsions in probands were not predictive of definite OCD in case first-degree relatives $(\mathrm{HR}=1.89,95 \% \mathrm{CI}=0.39-3.39, P=0.117)$.

The lifetime prevalence of definite OCD was higher in the first-degree relatives of case probands with ordering compulsions than in the first-degree relatives of case probands without such compulsions (33.3\% vs. $17.4 \%$ ). The difference between the two subgroups of first-degree relatives increased when subthreshhold OCD was included in the phenotype $(45.4 \%$ vs. $18.8 \%)$. A significant difference between the two subgroups of relatives in rates of definite and subthreshold OCD was confirmed by a log-rank test of survivor functions (log-rank $\left.\chi^{2}{ }_{1}=6.30, P=0.012\right)$. Figure 1 presents the KaplanMeier survivor functions comparing the age at onset of $\mathrm{OC}$ symptoms in the two subgroups of relatives. Onset age of OC symptoms was significantly later in the first-degree relatives of case probands with ordering compulsions than in first-degree relatives of case probands without such compulsions $(14.75 \pm$ 7.58 vs. $9.54 \pm 3.78$ years, mean $\left.\pm \mathrm{SD} ; \mathrm{t}_{25}=2.28 ; P=0.034\right)$. However, there was no significant difference in the onset age of OC symptoms in first-degree relatives according to whether the relatives themselves had a history of ordering compulsions.

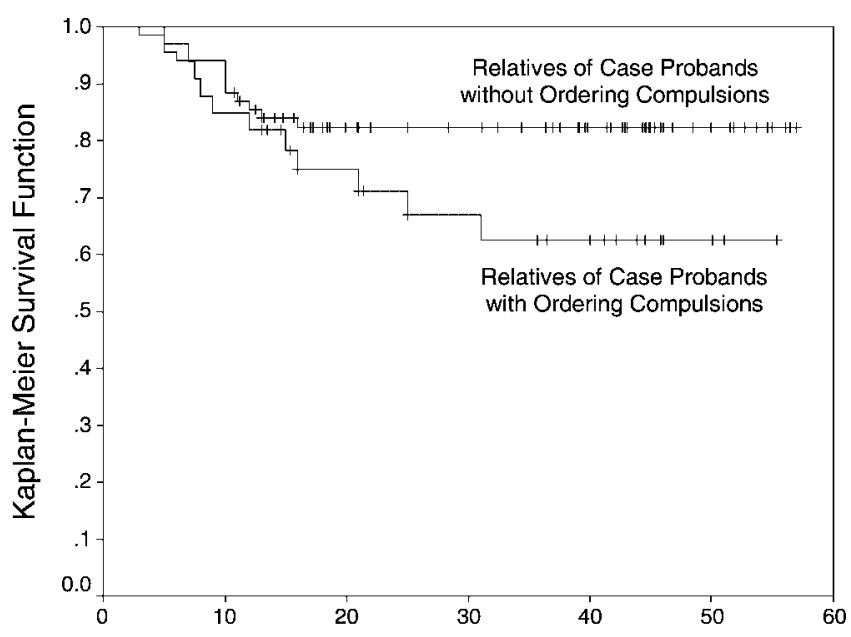

Age at Onset of Obsessive-Compulsive Symptoms

Fig. 1. Age at onset of obsessive-compulsive (OC) symptoms in firstdegree relatives of case probands with ordering and arranging compulsions versus first-degree relatives of case probands without such compulsions (log-rank $\chi_{1}^{2}=6.30, P=0.0121$ ).
A diagnosis of definite OCD was made in $57.1 \%$ of the case first-degree relatives with a history of tic disorder, but in only $20.9 \%$ of the case first-degree relatives without a tic history $(\mathrm{OR}=5.40,95 \% \mathrm{CI}=1.60-18.30, P=0.007)$. Conversely, a diagnosis of tic disorder was made in $18.2 \%$ of the case firstdegree relatives with definite OCD, but in only $4.2 \%$ of the case first-degree relatives without definite OCD. Age at onset of OC symptoms in the first-degree relatives was not influenced by tic history in either the proband $(13.43 \pm 4.94$ vs. $11.96 \pm$ 8.44 years, mean $\pm \mathrm{SD} ; \mathrm{t}_{20.97}=0.56 ; P=0.58$ ) or the relative $\left(12.24 \pm 5.25\right.$ vs. $12.25 \pm 12.84$ years, mean $\pm \mathrm{SD} ; \mathrm{t}_{3.18}=0.002$; $P=0.999$ ).

\section{DISCUSSION}

\section{Familiality of OCD and Tic Disorders}

The increased rates of obsessions, compulsions, and OCD in the case first-degree relatives provide further evidence for the familiality of early-onset OCD. Definite OCD was increased 11fold in the case first-degree relatives. With subthreshold OCD included in the phenotype, the finding was more robust. The lifetime prevalence rate of definite OCD in the control firstdegree relatives is consistent with rates from recent epidemiological [e.g., Weissman et al., 1994] and family studies [e.g., Nestadt et al., 2000]. Obsessions and compulsions were equally specific to the familial aspect of the phenotype. However, inclusion of subthreshold forms of obsessions or compulsions weakened the evidence for the familiality of the phenotype, suggesting that subthreshold symptoms may include more innocuous thoughts and behaviors unrelated to OCD.

The rate of definite OCD in the case first-degree relatives of $22.5 \%$ is much higher than the rates of $10.3 \%$ and $11.7 \%$ reported in the controlled family studies with adult probands by Pauls et al. [1995] and Nestadt et al. [2000], respectively. It is also somewhat higher than the rates in first-degree relatives reported in previous family studies with pediatric probands [Lenane et al., 1990; Leonard et al., 1992; Thomsen, 1995; Reddy et al., 2001]. The OR of 11.06 for definite OCD in the first-degree relatives is much higher than the summary OR of 4.0 from a meta-analysis of five family studies of OCD with adult probands [Hettema et al., 2001]. These differences are consistent, however, with previous family studies demonstrating that the aggregation of OCD is mainly concentrated in families of probands with early-onset OCD [Bellodi et al., 1992; Pauls et al., 1995; Nestadt et al., 2000].

In contrast to the findings with first-degree relatives, there were no significant differences in the rates of OCD phenotypes between case and control second-degree relatives. The rate of OCD in the second-degree relatives may have been underestimated because the majority of them were not directly interviewed, suggesting that the family history method is inadequate for assessing the familiality of OCD. Nonetheless, our OCD rate in case second-degree relatives of $1.6 \%$ is similar to the OCD rate of $1.4 \%$ found in the second-degree relatives of OCD probands in a previous study that primarily used the family history method [Cavallini et al., 1999].

Of the 35 case probands in our study, $22(63 \%)$ had at least one first-degree relative with either definite or subthreshold OCD. One case proband without an affected first-degree relative had two second-degree relatives with OCD based on family informant data. Thus, $66 \%$ of the probands could be considered as having familial OCD, providing further support for substantial heterogeneity in the familial aggregation of OCD [Bellodi et al., 1992; Pauls et al., 1995; Nestadt et al., 2000].

There were no significant differences in the rates of tic disorders between case and control first-degree relatives. However, our rate of all tic disorders in case first-degree relatives of $7.1 \%$ is consistent with rates ranging from $5.0 \%$ to 
$14.0 \%$ reported for first-degree relatives of early-onset OCD probands in previous studies [Leonard et al., 1992; Pauls et al., 1995; Grados et al., 2001]. The relatively high rate of tics in control relatives and the rather small sample size probably compromised the detection of a statistically significant increase in tics among case relatives [Zohar et al., 1992].

\section{Correlates of OCD in Case Relatives}

Two variables, ordering compulsions in case probands and tic disorders in case first-degree relatives, predicted a diagnosis of definite OCD in those relatives. The rate of definite OCD in the first-degree relatives of probands with ordering compulsions was about twice as high as the rate in relatives of probands without such compulsions. That difference was somewhat larger with subthreshold OCD included in the phenotype.

The effect of ordering compulsions on the familiality of OCD was suggested by a segregation analysis that found the relative risk of OCD was higher in relatives of probands with higher factor scores for symmetry and ordering symptoms [Alsobrook et al., 1999]. A segregation analysis of OC symptom dimensions in sibling pairs with Tourette's disorder indicated that the transmission of symmetry and ordering behaviors is consistent with dominant inheritance [Leckman et al., 2003]. In our study, $45.4 \%$ of case first-degree relatives of probands with ordering compulsions had either definite or subthreshold OCD, which is consistent with a dominant Mendelian model. These findings altogether suggest that ordering compulsions may characterize a more familial and possibly more etiologically homogeneous form of OCD. The possible association between ordering compulsions and the familial aggregation of the disorder requires replication.

The rate of definite OCD in the case first-degree relatives with tics was over twice as high as the rate in case first-degree relatives without tics. Conversely, the rate of tic disorders in case first-degree relatives with definite OCD was over four times as high as the rate of tic disorders in case first-degree relatives without definite OCD. This is consistent with previous reports of a higher prevalence of tics in case relatives with OCD than in those without OCD [Pauls et al., 1995; Grados et al., 2001] and provides support for a bidirectional relationship between OCD and tics. In contrast, the diagnosis of OCD in case first-degree relatives was not associated with a history of tics in case probands. This is consistent with previous studies that found no relationship between a history of tics in OCD probands and the diagnosis of OCD in their relatives [Leonard et al., 1992; Pauls et al., 1995; Nestadt et al., 2000; Grados et al., 2001].

A previous family study of OCD with adult probands found that case relatives with a history of tics had a significantly earlier age at onset of OC symptoms than did those without tics [Grados et al., 2001]. However, our study did not detect a significant difference in onset age of OC symptoms in case relatives according to whether the probands or the relatives themselves had a tic history. This may have occurred because our sample size was limited or because the first-degree relatives with OCD and tics in our study had a wide range in onset ages of OC symptoms.

The rates of OCD phenotypes in case first-degree relatives in our study were not influenced by the gender of either the proband or the relative. Two family studies with adult probands also found no relationship between gender and prevalence of OCD in first-degree relatives [Pauls et al., 1995; Nestadt et al., 2000]. However, a family study with pediatric probands found that the rates of both OCD and tic disorders were significantly higher in male relatives [Leonard et al., 1992].

Age at onset of OC symptoms in the case probands was not associated with the prevalence of OCD in their first-degree relatives. This suggests that it may be difficult to detect such an association with pediatric probands because of the narrow range in their onset ages, and that the risk for developing OCD in first-degree relatives has minimal variation in relation to a proband onset age range of $4-14$ years. If this pattern is replicated in other family studies with pediatric probands, the threshold for defining early-onset OCD could be considered to be as high as 14 years.

\section{Limitations}

Several limitations of our family study require comment. The inclusion of younger siblings at risk for developing OCD may have resulted in an underestimate of OCD prevalence in first-degree relatives. Similarly, older relatives may have underreported OC symptoms experienced earlier in life. However, our analyses did not suggest that either of these potential biases significantly influenced our results. Case probands were recruited mainly through a tertiary health care center, so that the case families in our sample may not be representative of families with pediatric OCD probands in the general population. Although control probands had no history of psychopathology, their families may have volunteered to participate because of concerns about mental health problems. Only a minority of subjects were genotyped, so that the biological relationships of some individuals may have been misclassified. We used DSM-III-R criteria which, in contrast to DSM-IV criteria, do not require obsessions to cause marked anxiety or distress for them to be classified as definite obsessions. We also used a simpler method for categorizing OC symptoms than the one used by Mataix-Cols et al. [1999] that assigned OC symptom category scores ranging from 0 to 2 . The use of a more dimensional method may have lead to different results in our analyses with ordering compulsions. The number of directly interviewed subjects was low so that the statistical power in the comparisons of case and control first-degree relatives was modest.

\section{CONCLUSIONS}

The results from our family study indicate that early-onset OCD is highly familial with substantially higher OR and relative risk estimates than those previously reported in family studies of OCD with adult probands [Hettema et al., 2001]. The familiality of early-onset OCD was also confirmed using robust Cox regression analyses. Thus, the study provides further support for the validity of subtyping OCD according to age at onset of OC symptoms [Sobin et al., 2000]. The study also suggests that a history of ordering compulsions in pediatric probands with OCD and comorbid tic disorders in case firstdegree relatives is associated with the familial aggregation of OCD. The results from our study require replication by other controlled family studies using pediatric probands. Such studies are likely to inform efforts to identify genetic factors involved in the etiology of early-onset OCD.

\section{ACKNOWLEDGMENTS}

The authors thank Diane Q. Koram, MSW, Kristin R. Chadha, MSW, Katherine J. Gold, MSW, MD, and Aileen H. Prout, MSW for their diagnostic interviews and Heidi L. Upchurch, B.S. for assistance with statistical analyses. The authors are especially thankful to the families who participated in the study.

\section{REFERENCES}

Alsobrook JP II, Leckman JF, Goodman WK, Rasmussen SA, Pauls DL. 1999. Segregation analysis of obsessive-compulsive disorder using symptom-based factor scores. Am J Med Genet Neuropsychiatr Genet 88:669-675. 
American Psychiatric Association Committee on Nomenclature and Statistics. 1987. Diagnostic and Statistical Manual of Mental Disorders. 3rd edn. Revised. Washington, DC: American Psychiatric Association. 245p.

Bellodi L, Sciuto G, Diaferia G, Ronchi P, Smeraldi E. 1992. Psychiatric disorders in the families of patients with obsessive-compulsive disorder. Psychiatry Res 42:111-120.

Burke KC, Burke JD Jr, Regier DA, Rae DS. 1990. Age at onset of selected mental disorders in five community populations. Arch Gen Psychiatry 47:511-518.

Cavallini M, Pasquale L, Bellodi L, Smeraldi E. 1999. Complex segregation analysis for obsessive compulsive disorder and related disorders. Am J Med Genet Neuropsychiatr Genet 88:38-43.

Clifford CA, Murray RM, Fulker DW. 1984. Genetic and environmental influences on obsessional traits and symptoms. Psychol Med 14:791-800.

Cox DR. 1972. Regression models and life tables. J R Stat Soc 34:187-220.

Fleiss JL. 1973. Statistical methods for rates and proportions. New York, NY: John Wiley and Sons.

Geller D, Biederman J, Jones J, Park K, Schwartz S, Shapiro S, Coffey B. 1998. Is juvenile obsessive-compulsive disorder a developmental subtype of the disorder? A review of the pediatric literature. J Am Acad Child Adolesc Psychiatry 37:420-427.

Goodman W, Price L, Rasmussen S, Mazure C, Fleischmann R, Hill C, Heninger G, Charney D. 1989. The Yale-Brown Obsessive Compulsive Scale: I. Development, use, and reliability. Arch Gen Psychiatry 46: 1006-1011.

Grados MA, Riddle MA, Samuels JF, Liang K-Y, Hoehn-Saric R, Bienvenu OJ, Walkup JT, Song D, Nestadt G. 2001. The familial phenotype of obsessive-compulsive disorder in relation to tic disorders: The Hopkins OCD Family Study. Biol Psychiatry 50:559-565.

Hanna GL, Veenstra-VanderWeele J, Cox NJ, Boehnke M, Himle JA, Curtis GC, Leventhal BL, Cook EH. 2002. Genome-wide linkage analysis of families with obsessive-compulsive disorder ascertained through pediatric probands. Am J Med Genet Neuropsychiatr Genet 114:541-552.

Hettema JM, Neale MC, Kendler KS. 2001. A review and meta-analysis of the genetic epidemiology of anxiety disorders. Am J Psychiatry 158: 1568-1578.

Hollingshead AB. 1965. Two factor index of social position. New Haven, CT: Yale University Department of Sociology.

Jonnal AH, Gardner GO, Prescott CA, Kendler KS. 2000. Obsessive and compulsive symptoms in a general population sample of female twins. Am J Med Genet Neuropsychiatr Genet 96:791-796.

Leckman JL, Sholomskas D, Thompson WD, Belanger A, Weissman MM. 1982. Best estimate of lifetime psychiatric diagnoses: A methodological study. Arch Gen Psychiatry 39:879-883.

Leckman JF, Pauls DL, Zhand H, Rosario-Campos MC, Katsovich L, Kidd KK, Pakstis AJ, Alsobrook Robertson MM, McMahon WM, Walkup JT, van de Wetering BJM, King RA, Cohen DJ. 2003. Obsessive-compulsive symptom dimensions in affected sibling pairs diagnosed with Gilles de la Tourette Syndrome. Am J Med Genet Neuropsychiatr Genet 116B: 60-68.

Lee ET, Go OT. 1997. Survival analysis in public health research. Ann Rev Public Health 18:105-134.

Lenane MC, Swedo SE, Leonard H, Pauls DL, Sceery W, Rapoport J. 1990. Psychiatric disorders in first-degree relatives of children and adolescents with obsessive-compulsive disorder. J Am Acad Child Adolesc Psychiatry 29:407-412.
Leonard HL, Lenane MC, Swedo SE, Rettew DC, Gershon ES, Rapoport JL. 1992. Tics and Tourette's disorder: A 2- to 7-year follow-up of 54 obsessive-compulsive children. Am J Psychiatry 149:1244-1251.

Liang K-Y, Pulver AE. 1996. Analysis of case-control/family sampling design. Genet Epidemiol 13:253-270.

Mannuza S, Fyer AJ, Endicott J, Klein DF. 1985. Family Informant Schedule and Criteria (FISC). New York, NY: Anxiety Disorders Clinic, New York Psychiatric Institute.

Mantel N. 1966. Evaluation of survival data and two new rank order statistics arising in its consideration. Cancer Chemother Rep 50:163170.

Mataix-Cols D, Rauch SL, Manzo P, Jenike M, Baer L. 1999. Use of factoranalyzed symptom dimensions to predict outcome with serotonin reuptake inhibitors and placebo in the treatment of obsessive-compulsive disorder. Am J Psychiatry 159:263-268.

Nestadt G, Samuels J, Riddle M, Bienvenu J, Liang K-Y, LaBuda M, Walkup J, Grados M, Hoehn-Saric R. 2000. A family study of obsessivecompulsive disorder. Arch Gen Psychiatry 57:358-363.

Orvaschel H. 1987. Schedule for Affective Disorders and Schizophrenia for School Aged Children-Epidemiologic Version (K-SADS-E), 4th edn. Philadelphia, PA: Medical College of Pennsylvania.

Pauls DL, Hurst CR. 1991. Schedule for Tourette and other behavioral syndromes. New Haven, CT: Child Study Center, Yale University.

Pauls DL, Alsobrook JP, Goodman W, Rasmussen S, Leckman JF. 1995. A family study of obsessive-compulsive disorder. Am J Psychiatry 152:7684

Reddy PS, Reddy YC, Srinath S, Khanna S, Sheshadri SP, Girimaji SR 2001. A family study of juvenile obsessive-compulsive disorder. Can J Psychiatry 46:346-351.

Rosario-Campos MC, Leckman JF, Mercadante MT, Shavitt RG, Prado HS Sada P, Zamignani D, Miguel EC. 2001. Adults with early-onset obsessive-compulsive disorder. Am J Psychiatry 158:1899-1903.

SAS Institute, Inc. 1997. SAS/STAT software: Changes and enhancements through Release 6.12. Cary, NC: SAS Institute, Inc.

Sobin C, Blundell ML, Karayiorgou M. 2000. Phenotypic differences in early- and late-onset obsessive-compulsive disorder. Comp Psychiatry 41:373-379

Spitzer RL, Williams JBW, Gibbon M, First MB. 1990. Structured Clinical Interview for DSM-III-R (SCID). Washington, DC: American Psychiatric Press, Inc.

Thomsen PH. 1995. Obsessive-compulsive disorder in children and adolescents: a study of parental psychopathology and precipitating events in 20 consecutive Danish cases. Psychopathology 28:161-167.

Valleni-Basile LA, Garrison CZ, Jackson KL, Waller JL, McKeown RE, Addy CL, Cuffe SP. 1994. Frequency of obsessive-compulsive disorder in a community sample of young adolescents. J Am Acad Child Adolesc Psychiatry 33:782-791.

Weissman MM, Bland RC, Canino GJ, Greenwald S, Hwu HG, Lee CK, Newman SC, Oakley-Browne MA, Rubio-Stipec M, Wickramaratne PJ, Wittchen H-U, Yeh E-K. 1994. The cross national epidemiology of obsessive compulsive disorder. The Cross National Collaborative Group. J Clin Psychiatry 55(Suppl):5-10.

Zohar AH, Ratzoni G, Pauls DL, Apter A, Bleich A, Kron S, Rappaport M, Weizman A, Cohen DJ. 1992. An epidemiological study of obsessivecompulsive disorder and related disorders in Israeli adolescents. J Am Acad Child Adolesc Psychiatry 31:1057-1061. 